\title{
Advanced Outage and Control Center: Strategies for Nuclear Plant Outage Work Status Capabilities
}

Gregory Weatherby

May 2012

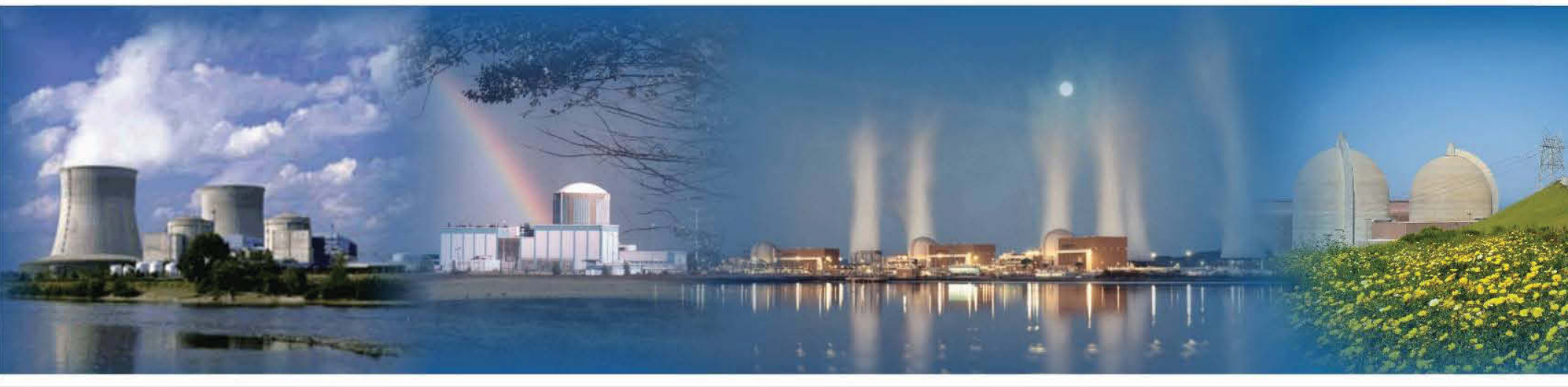

The INL is a U.S. Department of Energy National Laboratory operated by Battelle Energy Alliance 


\section{DISCLAIMER}

This information was prepared as an account of work sponsored by an agency of the U.S. Government. Neither the U.S. Government nor any agency thereof, nor any of their employees, makes any warranty, expressed or implied, or assumes any legal liability or responsibility for the accuracy, completeness, or usefulness, of any information, apparatus, product, or process disclosed, or represents that its use would not infringe privately owned rights. References herein to any specific commercial product, process, or service by trade name, trade mark, manufacturer, or otherwise, does not necessarily constitute or imply its endorsement, recommendation, or favoring by the U.S. Government or any agency thereof. The views and opinions of authors expressed herein do not necessarily state or reflect those of the U.S. Government or any agency thereof. 
INL/EXT-12-26197

Revision 0

\section{Advanced Outage and Control Center: Strategies for Nuclear Plant Outage Work Status Capabilities}

Gregory Weatherby

May 2012

Idaho National Laboratory

Idaho Falls, Idaho 83415

http://www.inl.gov

Prepared for the

U.S. Department of Energy

Office of Nuclear Energy

Under DOE Idaho Operations Office

Contract DE-AC07-05ID14517 



\section{EXECUTIVE SUMMARY}

This research project successfully developed and deployed new technologies that will assist nuclear power plant outage managers in conducting more efficient and error-free outages. This research is important because nuclear utilities spend millions of dollars of scarce resources conducting outages at their plants each year. A reduction in cost to conduct an outage translates into a savings to the utilities that keeps the nuclear industry competitive with other energy sources.

A nuclear plant outage is huge, complex undertaking involving thousands of activities typically over the course of three to four weeks. A particular need in outage management is the ability to determine, communicate, and assess outage work status on a timely basis to support the real-time decision making in order to react to changes and additions to the work plan. This research project investigated new concepts in managing work activities such that timely reporting and dissemination of work status and other important work process parameters was inherently accomplished through the application of digital technologies.

This report summarizes the research logic and technology deployment strategies used to demonstrate that outages can be improved through the strategic use of collaborative software applications and commercially available handheld technologies. The report contains the research methods, collaboration efforts, and conclusions of the research team. In summary, the research team found that commercially available communication technologies, when linked with webbased collaborative software applications, represent a relatively inexpensive solution to improving outage management techniques. While these individual technologies exist in the marketplace, they are not useful to outage managers until they are applied in a way that allows outage management teams to make consistent and strategic decisions during an actual outage activity.

Three keys players collaborated to produce this foundational work. INL researchers provided the leadership, vision and direction needed to aggregate stand-alone technologies into a process for improving work status capabilities, Exelon nuclear provided the facilities to demonstrate the technologies, and Ovalpath developed the database capabilities that supported the improved communication capabilities.

The outage research team, along with its participating industry partners, recommends continued research and refinement of the fundamental capabilities demonstrated in this report. There is a strong expectation that when fully developed, these methods will be applied across the industry to greatly improve the practice of nuclear outage management in the United States. 


\section{ACKNOWLEDGEMENTS}

The Outage research team would like to acknowledge the efforts of the following individuals and organizations that made this research possible.

Keith Moser and members of the Exelon Nuclear Byron plant for hosting the field demonstration activities,

Ralph Aceves and the professional staff at Ovalpath for their role in the development of the software used in this technology demonstration,

Dr. David Gertman, Ken Thomas, Samy Tawfik and Jacques Hugo of the INL Human Factors Group for the development of the field assessment logic and assessment criteria, and

Katya Le Blanc and Johanna Oxstrand of the INL Human Factors Group for their technical review expertise and management of the final document. 


\section{CONTENTS}

EXECUTIVE SUMMARY iii

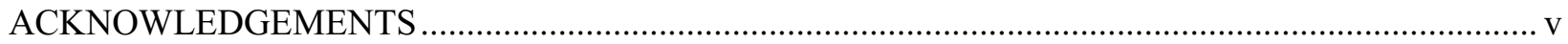

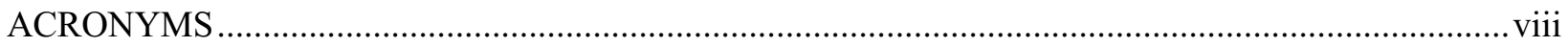

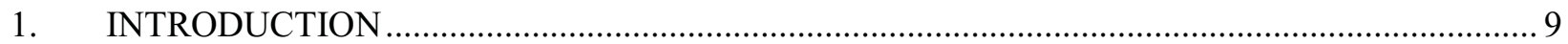

2. METHOD

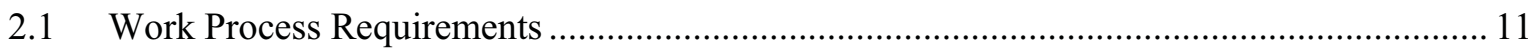

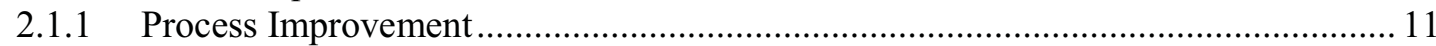

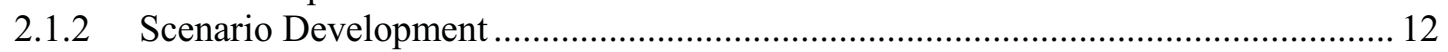

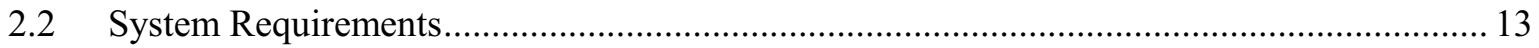

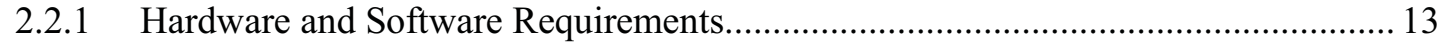

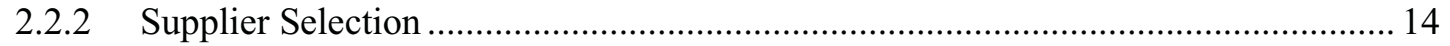

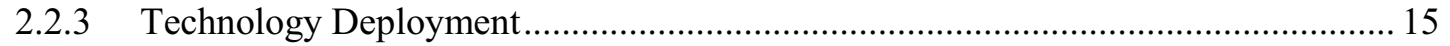

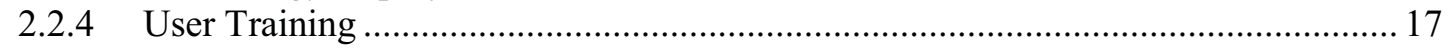

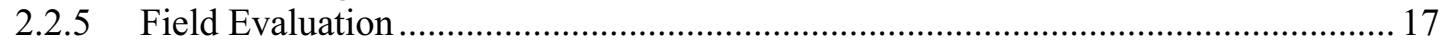

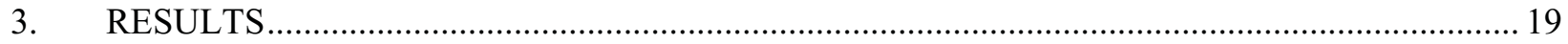

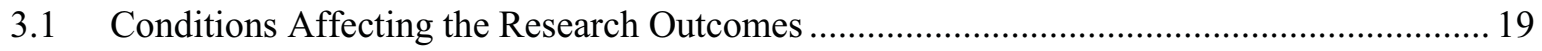

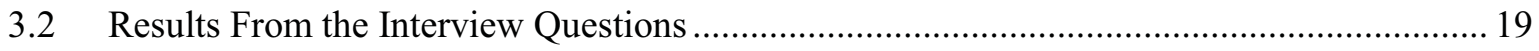

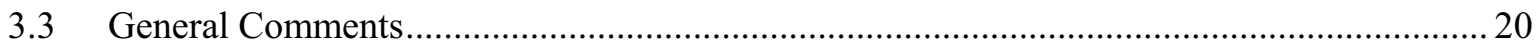

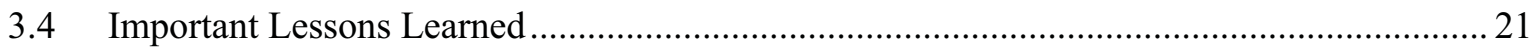

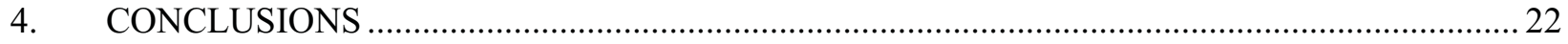

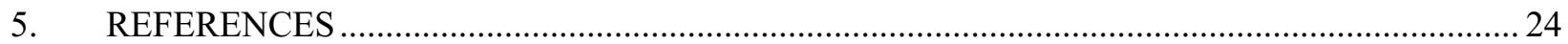

Appendix A LWRS Pilot Project Technology Demonstration: Increasing Efficiency of

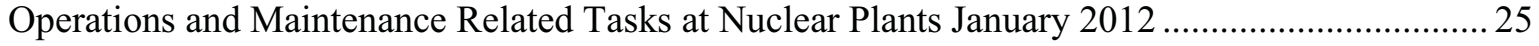

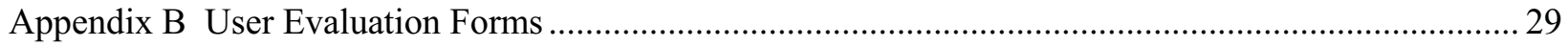

\section{FIGURES}

Figure 1 Hand-held Selections for Demonstration.

Error! Bookmark not defined.

Figure 3 Screen Display of "Facebook" Configuration Dislpay in Scrolling Format............................. 15

Figure 2 Pre-Test Checking of Barcode Scanning Capability ............................................................ 15

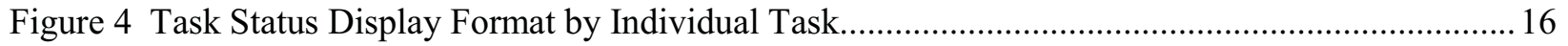

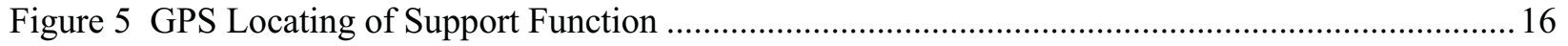

Figure 6 The Process of Information Sharing While Executing a Task................................................. 17 


\section{ACRONYMS}

AOC

BEA

COTS

CRADA

DOE

EPRI

HU

ICC

II\&C

INL

INPO

LWRS

MCR

NEO

NPP

$\mathrm{OE}$

OCC

COTS

$\mathrm{RCV}$

$\mathrm{RD} \& \mathrm{D}$

SA

SIG

UWG

WEC
Advanced Outage Coordination

Battelle Energy Alliance

Commercial off the shelf

Cooperative Research and Development Agreement

Department of Energy

Electric Power Research Institute

Human Performance

Information \& Communication Center

Instrumentation, Information, and Control

Idaho National Laboratory

Institute of Nuclear Power Operations

Light Water Reactor Sustainability

Main Control Room

Nuclear Equipment Operator

Nuclear Power Plant

Operating Experience

Outage Control Center

Commercial Off-The-Shelf Technology

Remote Concurrent Verification

Research Development, Demonstration, and Deployment

Situation awareness

Special Interest Group

Utility Working Group

Work Execution Center 


\section{INTRODUCTION}

The research effort is a part of the Light Water Reactor Sustainability (LWRS) Program. LWRS is a research and development program sponsored by the Department of Energy, performed in close collaboration with industry to provide the technical foundations for licensing and managing the long-term, safe and economical operation of current nuclear power plants. The LWRS Program serves to help the US nuclear industry adopt new technologies and engineering solutions that facilitate the continued safe operation of the plants and extension of the current operating licenses.

In the LWRS research pathway for Advanced Instrumentation, Information, and Control (II\&C) Systems Technologies, a series of pilot projects were defined as the roadmap for industry to collectively integrate new technologies into nuclear power plant work activities. A pilot project is an individual demonstration that is part of a larger strategy needed to achieve modernization according to a plan. It is small enough to be undertaken by a single utility, it demonstrates a key technology or outcome required to achieve success in the higher strategy, and it supports scaling that can be replicated and used by other plants. The Advanced Outage Coordination (AOC) Pilot Project was directed at carrying out the applied research for the development and pilot of technology designed to enhance safe outage and maintenance operations, improve human performance and reliability, increase overall operational efficiency, and improve plant status control.

Plant outage management is a high priority concern for the nuclear industry from cost and safety perspectives. Unfortunately, many of the underlying technologies supporting outage control are the same as those used in the 1980's. They depend heavily upon large teams of staff, multiple work and coordination locations, and manual administrative actions that require large amounts of paper. Previous work in human reliability analysis suggests that many repetitive tasks, including paper work tasks, may have a failure rate of 1.0E-3 or higher (Gertman et al., 2005). With between 10,000 and 45,000 subtasks being performed during an outage (Gomes, 1996), the opportunity for human error of some consequence is a realistic concern. Although a number of factors exist that can make these errors recoverable, reducing and effectively coordinating the sheer number of tasks to be performed, particularly those that are error prone, has the potential to enhance outage efficiency and safety.

Additionally, outage management requires precise coordination of work groups that do not always share similar objectives. Outage managers are concerned with schedule and cost, union workers are concerned with performing work that is commensurate with their trade, and support functions (safety, quality assurance, and radiological controls, etc.) are concerned with performing the work within the plants controls and procedures. Approaches to outage management should be designed to increase the active participation of work groups and managers in making decisions that closed the gap between competing objectives and the potential for error and process inefficiency.

According to an IAEA publication, (IAEA, 2006), what the industry needs is " .... monitoring system that incorporates a systematic review of actual results and compares these with expectations established by objectives. Nuclear power plant (NPP) management has to be able to respond promptly to any situation when... attributes are not achieve. The basic function of an outage monitoring system is to gather and evaluate quantitative and qualitative information for prompt and effective decision-making." (p. 3). Further, as with all work groups, the challenge is also to accommodate interaction of various units (management, supervision, vendors and crafts) with competing objectives as they share information with each other, and provide decision making capabilities towards achieving their shared goals (Mora, 2003).

In a previous effort, researchers in the AOC pilot project conducted a survey to determine what outage managers needed to become more efficient and to conduct outages with less error and increased safety. The answer was surprisingly simple, yet difficult to achieve. The managers said that they needed "Real-time Truth." Real-time truth refers to the ability of the outage manager to have the information he needs, when he needs it. It also refers to the ability for an outage manager to receive accurate and unbiased estimates of the status of the work that is currently underway. The availability of real-time truth 
would enable an outage manager to effectively and efficiently coordinate the complex work activities executed during an outage. Additionally, with real-time truth, outage managers might be able to recognize emerging issues earlier and coordinate plans to mitigate those issues before they become extensive and expensive problems.

Similarly in a report issued by the OECD Halden Reactor Project (Hildebrandt \& Koskinen, 2011), the researchers identified similar needs of outage teams. These included:

- Better anticipation of potential problems,

- More efficient work processes and teamwork,

- An increase in trust (between the management team and the field workers) that allows critical decisions to be made with high reliability,

- Real-time monitoring of task progress,

- Involvement of Operations personnel at the right time to make the right decisions,

- Providing the best information system possible with an emphasis on the importance of plant status in real-time.

As stated above, with thousands of entries and transcriptions being made during an outage, a moderate to high error propensity exists. Automation of some of this paper work can reduce the sheer number of manual, clerical activities and thus contribute to increased reliability during outages.

One way to meet the objectives above is to eliminate many of the paper-based tasks and increase communication and coordination by providing mobile devices with electronic procedures. Many of the error-prone subtasks associated with outage management can be eliminated if information can be directly transmitted from the field to where it is needed and vice versa. The ability to integrate hand held mobile device technology and software into the outage management process, emphasizing streamlining of accounting, communication, and data management coordination in the near term has enormous potential. For example, the reduction in labor by lessoning the need for manual cross checking has a significant financial impact. Ultimately, implementing technology has the impact of being a force multiplier.

However, there may be significant challenges associated with introducing new technology into Nuclear Power Plants. Previous research performed by researchers in the AOC pilot project suggests that the nuclear industry has been slow to embrace and deploy more advanced technologies to manage outages. This is widely thought to stem from traditional beliefs that existing processes are known to work and are reliable to the extent necessary to perform outage work (yet not as efficient as possible in today's business environment), a reluctance to experiment with technology that is not well understood, and a resistance to change processes that include security and regulatory hurdles.

In order for the nuclear industry to feel comfortable implementing new technology there needs to be existing evidence of how the technology can improve efficiency and reduce errors. To this end, INL researchers, working closely with Exelon's Byron nuclear station personnel, sought to create a technology-based system that would address industry needs and result in increased safety and efficiency for the benefit of all U.S. nuclear plants. The goal of this research effort is to develop outage work status capabilities, providing a means for communicating work progress and completion status directly from field activities to the outage control centers. Our strategy was developed to transform the current outage control and maintenance approaches by working with industry to seek opportunities to improve these processes using plant experience, human factors research techniques, and deploying, where possible, technology such as handheld devices, team visualization approaches (e.g., Smart Boards), and software architecture allowing for real-time status updating of field activities. Over time, success in this area will result in more efficient, error-reduced outages that assist nuclear power plants in reducing overall outage cost, thus, strengthening nuclear powers competitive posture with competing energy sources. 


\section{METHOD}

INL has conducted previous work in nuclear plant process improvement and application of digital technology to overcome work inefficiencies and human performance problems inherent in traditional, paper-based work processes. Improved outage safety and efficiency is very much a function of how well work processes are executed and is therefore, a research area that lends itself well to this type of approach. Based on discussions with utility partners and, in particular, Exelon Nuclear, the research team developed the following hypothesis:

\section{More efficient and safer outage tasks are enabled by a technology-based system in which real- time outage work status information reveals potential issues before they become problems, supports a shared problem solving environment, and facilitates high quality decision making.}

The research team determined that the best method for testing this hypothesis was to build upon the work the INL and Exelon had completed during 2011 at the Byron NPP. In 2011, INL researchers and Exelon management had developed and deployed an integrated information sharing approach using SMART Technologies SMART Board ${ }^{\mathrm{TM}}$ interactive displays and SMART Technologies Bridgit ${ }^{\mathrm{TM}}$ conferencing software. This enabled outage managers to communicate between the plant's Outage Control Center, Work Execution Center, and other remote platforms equipped with the SMART technologies. See Light Water Reactor Sustainability Report Advanced Instrumentation Information and Control (II\&C) Facility Build-out and Project Execution of LWRS II\&C Pilot Projects 1, 2, \& 3 (Oxstrand, Boring \& Farris, 2011).

In January of 2012 the INL research team developed a Pilot Project Technology Demonstration Plan to guide the field demonstration project (See Appendix A).

\subsection{Work Process Requirements}

The research team, working closely with the Exelon Byron NPP Operations management, selected a work process to be used for the deployment of a prototype technology-based work process system to demonstrate how new work process concepts and applied technology can readily enable the accurate and timely determination of work status. The criteria for selection of the work process were:

- The process must require an interface between field personnel and the OCC and/or WEC,

- The process must be common to outage activities,

- The process must require the creation of logs or records,

- The process must be repeatable over several iterations to allow a comparison of several hand-held technologies and the software configuration, and

- The process must be detailed enough to allow the research team sufficient judgment on the capabilities of the system.

Based on these criteria, the research team selected an Operations procedure; Control of Equipment and System Status (Exelon OP-AA-108-101) as the candidate work process. The purpose of this procedure is to control activities involving equipment manipulations in order to maintain proper operational configuration of plant systems. This procedure is also intended to prevent the misalignment of components resulting from an inappropriate action (or inaction) which ultimately results in placement of a device in a configuration other than that intended by drawings, procedures, clearances, or other similar documents.

\subsubsection{Process Improvement}

The research team was provided a copy of the Exelon procedure and began mapping the procedure step-by-step. The approach to this work involved the application of proper work process design and human performance elements to reconstruct the process in a manner that improved performance without 
introducing additional negative factors. For example, in moving from a paper-based work process to one that involves the use of computer systems and hand-held electronic tablets, it was important to not introduce new forms of worker mistakes due to lack of competence with the technology. There were many other human factors considerations such as ergonomics, portability of the digital devices, ambient lighting, ambient environmental conditions (radiation, dust, temperature extremes), interference with personal protective equipment (gloves, safety glasses), and so forth.

The work process design applied concepts that are not possible in a paper-based process. These included the ability to make work status updates an automatic action of the system as any particular work step was accomplished. The research team developing the format, presentation, and logic of computerbased work instructions to guide the field worker through the steps in the right sequence and to react to both permissible and impermissible inputs from the worker. They determined where work steps could be performed by the system in parallel rather than sequentially, reducing effort and time delays. They also determined where information that needed to be entered into the application or could be obtained from corporate data bases, again eliminating the effort and possible creation of errors in entering this information manually. In short, the process was redesigned by exploiting the technology to enhance all aspects of the tasks by reducing manual effort, retrieving and inserting needed information, automatically updating work status, automatically creating job logs, and automatically updating process-related data bases. The key point is, that in this improved work process, the worker would simply execute his assigned tasks and all of the auxiliary functions of communicating status, creating logs, and updating data bases, would be executed by the system as background functions. Thus, everyone involved in the job, from managers, to outage work controllers, to other workers - would be kept completely up-to-date with the work status without interrupting the efforts of the worker.

\subsubsection{Scenario Development}

To illustrate the use of this enhanced work process and to confirm the hypothesis, the following scenario was developed by the research team and executed by the Byron NPP Operations staff in a demonstration conducted in the Byron NPP turbine building in February, 2012.

a. An emergent plant issue is identified of an abnormal equipment condition that needs the application of Control of Equipment and System Status procedure.

b. An operations supervisor initiates a work item for the execution of this procedure on the subject equipment and assigns it to an operating crew. The work item is then approved for start of work.

c. All members of that crew are notified on their hand-held electronic device (tablet, PDA, or smart phone) and one of the available field operators signifies through the system that he can execute the task.

d. The system notifies the supervisor of the individual that will execute the task and that work is starting.

e. The field operator travels to the equipment location, picking up equipment tags from an area printer.

f. The field operator executes the procedure, first verifying the appropriate equipment identification by reading the equipment label bar code with his hand-held device.

g. That information is then sent to the task supervisor (or outage control manager) and the task is authorized.

h. The field operator follows the steps in the work instructions on his hand-held device until completion. Each step in equipment tagging and positioning is photographed to create an auditable record of the work being correctly performed. 
i. As each step is completed, an automatic update of the job status is transmitted to the outage control center where work progress can be evaluated and subsequent coordination actions taken to minimize the lag time between task steps or supporting actions (i.e., supervisory oversight, QA inspections, mobilization of other work teams, etc.)

j. The field operator is able to send a live video stream to his supervisor to discuss a particular question about the work. He is able to get immediate work direction without leaving the job location.

k. All data bases are updated with required information either about the job status or the technical information of the equipment tags.

1. Work status as the operator moves from one piece of equipment to another is automatically posted to the Work Execution Center, and then through the coupling of the SMART boards, to the Outage Control Center. Any other type of device used by managers and workers are able to receive the same work status updates in real-time.

m. Following a simulated 30-day time lapse, the procedure requires verification that the tags are still in place. The work item is automatically generated by the system and sent to the Operations manager for work assignment and approval, repeating Step b.

n. Similar actions follow as above for the field operator performing the verification.

\subsection{System Requirements}

Based on the work process redesign, human factors considerations, and scenario performance elements, the research team developed the system requirements and selected the technology components to support the pilot project demonstration.

\subsubsection{Hardware and Software Requirements}

During the demonstration planning phase, the research team discussed which hand-held products should be included in the demonstration. A web-based work process and data capture technology was also needed that could function on Android, iOS (Apple/Mac), Blackberry, Windows Mobile devices. A number of hand-held devices were evaluated for possible inclusion in the demonstration. Each device was given a rating based on several criteria including: ease of use and handling, portability, screen size and resolution, and price. The research team (INL, Exelon and Ovalpath) developed functional attributes for the hardware and software. They included:

- A handheld device with high end-user acceptability that could transmit and receive data, voice, video, still photo's,

- A device that could read bar-codes and compare the scan with a known database of plant barcodes,

- A device that would be cost effective to use in nuclear plants and that was capable of withstanding day-to-day use by plant personnel,

- A software system that could capture and record important information on procedure or job task status, field conditions, and allow two way transmission of that information between field elements and outage management in real time,

- Be capable of interfacing with the SMART board technology already in place at the Byron plant,

- Be capable of displaying the real-time status of multiple work tasks (in this case multiple uses of the procedure at any one time),

- Interact seamlessly with the plants wireless communication capabilities, 
- Be capable of locating plant personnel through the use of GPS technology,

- Be capable of creating a historical record, complete with video, photo's, time stamping, and forms, that could be used for:
$\circ \quad$ Real-time outage management statusing
- Future pre-job briefings
$\circ$ Shift turn-over briefings,
- Training,
- Process efficiency reviews and scheduling strategies, and
- Accurate records of work performed in the field

Based on the requirements listed above, the hardware selected included:

- Apple iPad (12")

- Apple Touch

- Samsung Galaxy 5"

- Acer Iconia Tab 10"

- Apple iPhone 4S

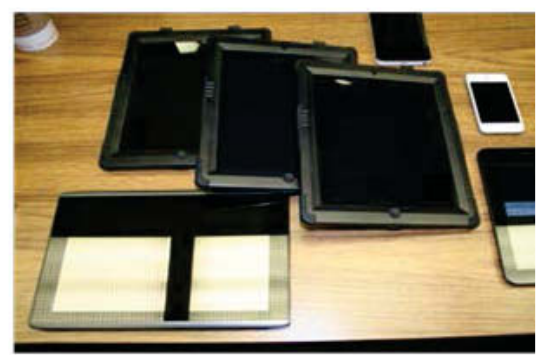

Figure 1 Hand-held Selections for Demonstration

\subsubsection{Supplier Selection}

The research team conducted a literature and web-based search of suppliers that could provide connectivity to the OCC and WEC, as well as other links important to decision-making during outage and emerging issues management. The objective was to use a capability that could be utilized by US nuclear plants as soon as possible and to avoid having to design and build a complex foundational system from the ground up. The information the team found fell into the following categories:

- Suppliers that were large and established that offered their products commercially and were resistant to altering their products to meet the needs of the NPP's,

- Suppliers that could alter their products, but at a high cost,

- Suppliers that were willing to alter their products or develop new products, but could not accomplish the desired outcomes within a short time period, and

- Suppliers that were small, willing to work with the research team, had an existing related product, and were nimble enough to alter their existing product to meet the research team's and the plant's needs.

The research team chose to work with the smaller supplier who could work closely to develop capabilities in the short term. An agreement was finalized with Ovalpath Inc, of San Jose, California to develop the software platform from one of their existing products. 
Members of the INL/Exelon research team began discussions with Ovalpath on modifying their existing Wizzpers ${ }^{\mathrm{TM}}$ data capture technology to meet the objectives of the pilot project research. The INL research team coordinated the necessary system attributes using input from the Exelon team and from the Ovalpath technical development team.

\subsubsection{Technology Deployment}

The critical steps of the procedure were loaded onto the Wizzpers database which could be displayed on both the SMART boards and the hand-held devices simultaneously. In addition, a copy of the plants bar-code library was also loaded onto the database, see Figure 2. This would allow the software to interrogate the equipment bar-code tags to assure that the correct piece of equipment had been selected by the field team.

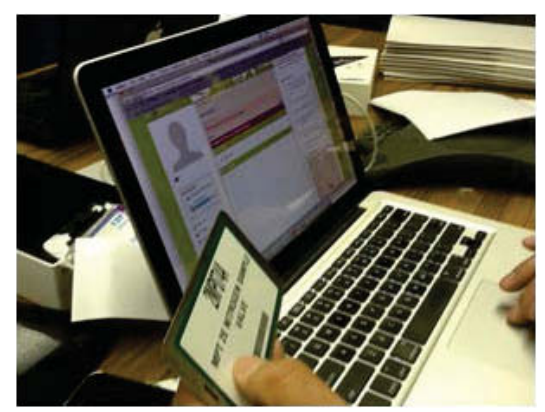

Figure 2 Pre-Test Checking of Barcode Scanning Capability
Once the procedure was loaded onto the Wizzpers system, the research team configured the various graphical user interfaces to track the progress of the procedure in real time. The user interfaces were accessed through handheld devices and SMART boards. For the purpose of the demonstration, the graphical user interfaces were designed to display status information in a number of different ways. The first user interface displays information much like a "Facebook" page where information is scrolled as it is received by the management team in the OCC, WEC, or other remote location.

The development of a "Facebook" type interface was considered important because it is a common user interface display and required little user training to acquire the skills for it's use.

This user interface allows managers to send and receive information such as safety updates, or other information much like text messaging, see Figure 3. The second user interface displays information in a task-based format that provides interactive capabilities to the OCC and WEC management team. As the status of the field activities change, the coloration of the display is automatically modified to alert the management team that action is needed to approve or disapprove field activities. This second interface is shown in Figure 4.

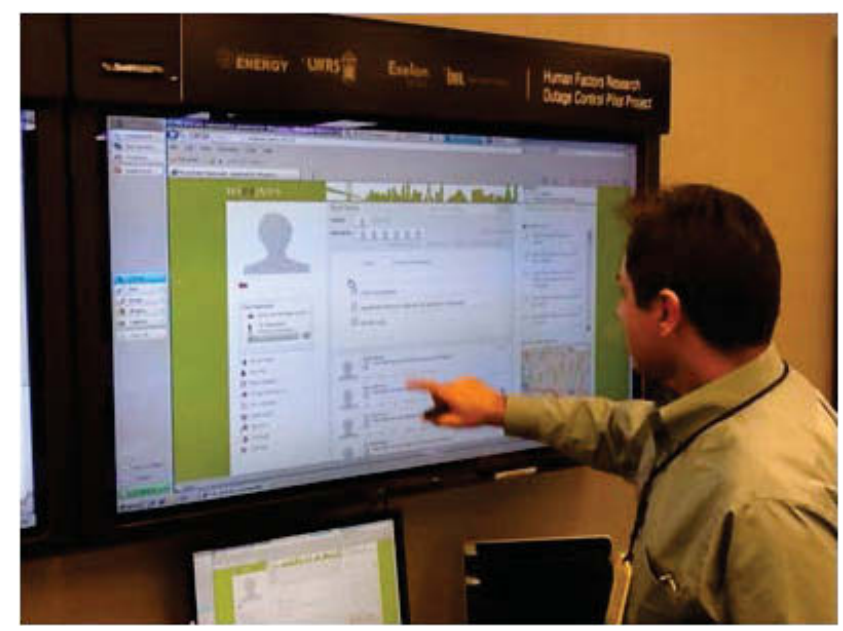

Figure 3 Screen Display of "Facebook" Configuration Display in Scrolling Format 


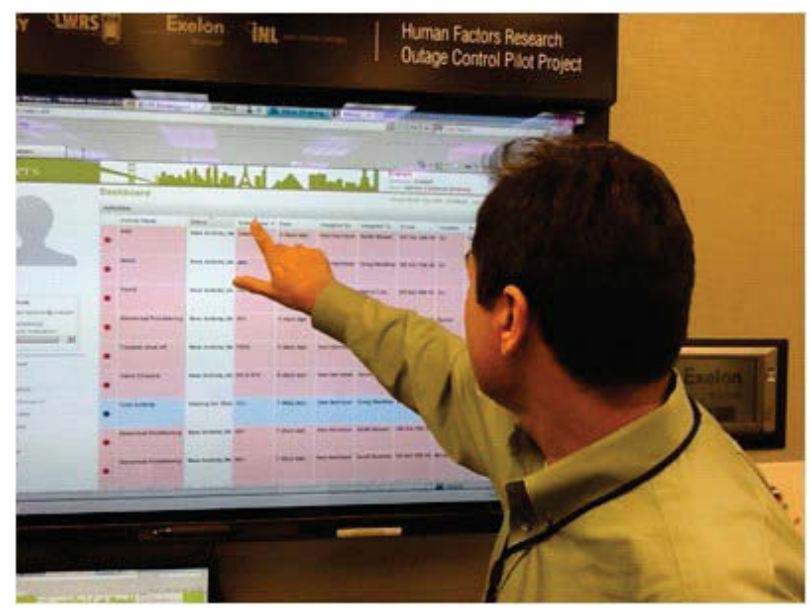

Figure 4 Task Status Display Format by Individual Task

Figure 5 depicts the third user interface, which displays the actual location of work teams in the field. It can also track and locate critical support personnel who need to be present for task completion. For example, if a Quality Inspector is needed to inspect a weld, the closest inspector can be located and sent to the work location immediately. The software can also locate inspection personnel when a designated step is reached in a procedure, alerting them to the request prior to the actual need time. This capability continues to be refined. The use of GPS technology to support this function in a NPP is not always reliable. Additional research efforts are being conducted to increase the capabilities of this function.

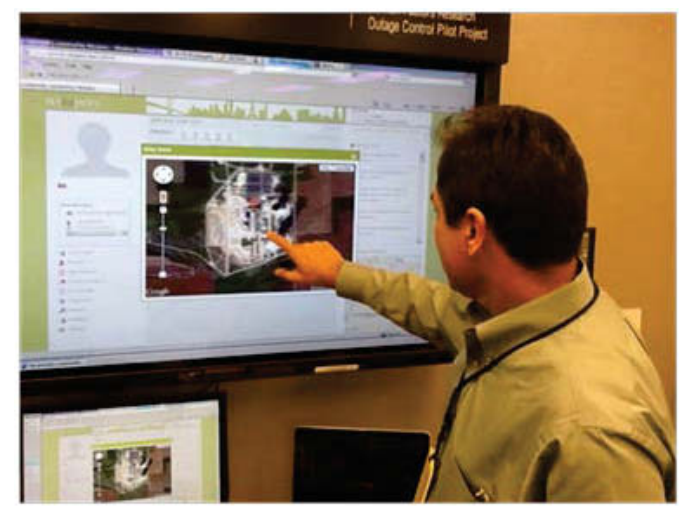

Figure 5 GPS Locating of Support Function

Figure 6 provides a logical flow of how the different user interfaces are used to provide valuable information and guidance to everyone involved in the execution of a task. The task lifecycle starts when the supervisor assigns the task to a field worker. The field worker is notified by the system (i.e., the program running on his handheld device) that a new task has been assigned to him. The field worker utilizes the technology when executing the task. The technology will help guide the field worker through the steps, provide means to conduct concurrent verification, ease the communication between the field worker, the WEC, and the OCC, etc. The supervisor will get continuous status updates, as well as other information sent from the field worker, during the execution of the task. The progress and status of the work can also be observed in the OCC, WEC, or at any other location. 


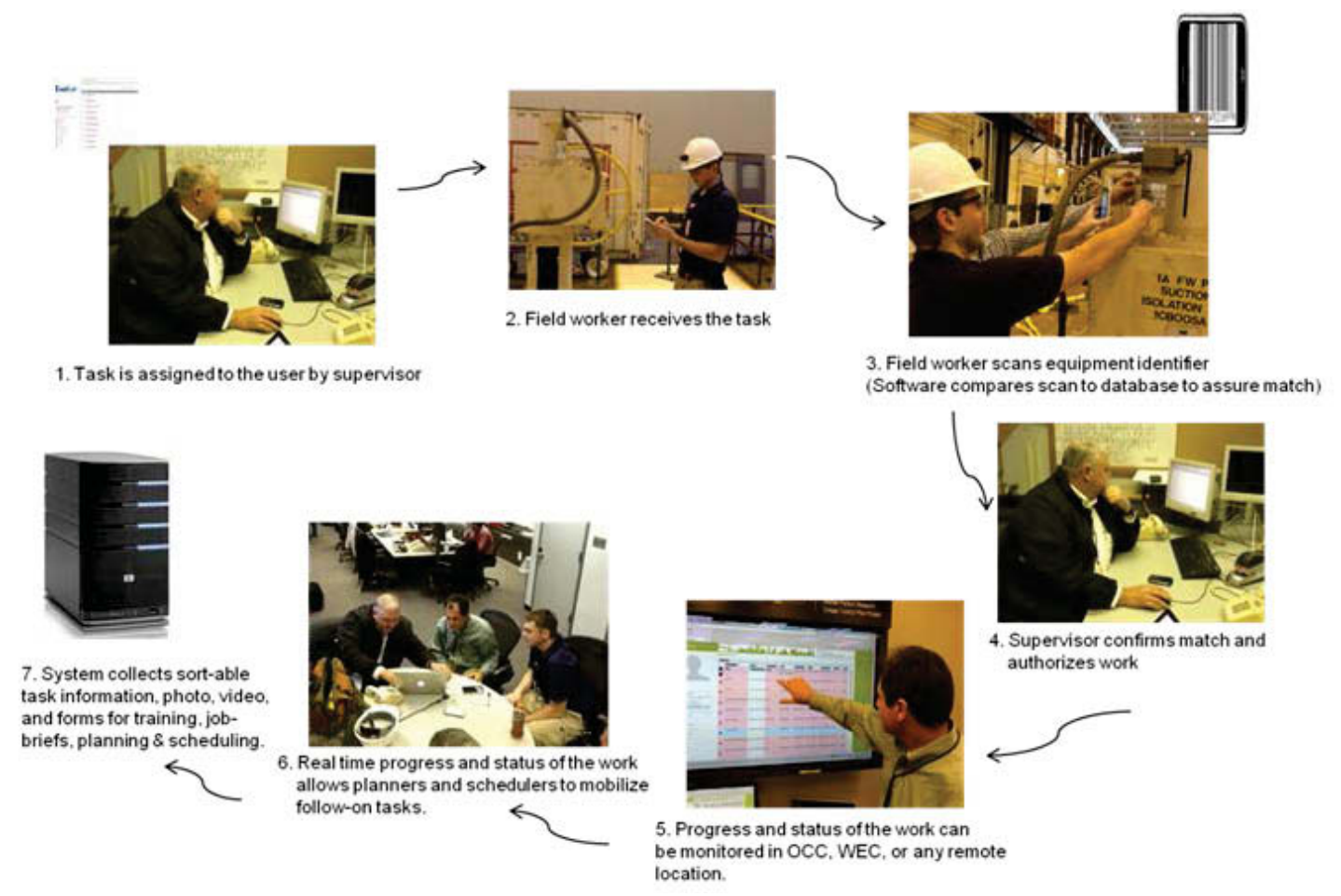

Figure 6 The Process of Information Sharing While Executing a Task

\subsubsection{User Training}

The research team created training for users of the Wizzpers and hand-held technology. The training was deployed prior to the field testing and combined both a process overview and a hands-on segment. All users were familiar with the procedure to be tested and had used it numerous times in actual field applications. The training was configured to achieve the following objectives:

- Familiarize the participants with the objectives of the study,

- Introduce the OCC, WEC, and field teams to the technology and its capabilities,

- Solicit feedback on the usability of the software, devices, and displays,

- Create an environment where new applications for the technology could be captured.

An important item to note is that training to achieve competence in this system was minimal and informal due to the "Facebook" type presentation of the Ovalpath software. Thus, plant workers who are familiar with this type of social media have an inherent understanding of how the system works and the use of the system is intuitive for them.

\subsubsection{Field Evaluation}

The INL Human Factors group developed a technology evaluation checklist and uploaded it to the hand-held devices as an icon on participant desktop computers prior to the demonstration. The evaluation checklists would allow the users to report their experience and recommendations in an anonymous fashion and consisted of the following:

- A Pre Trial Evaluation - This evaluation contained questions about the acceptability of the hardware and general usability of the device for its intended purpose. 
- A Post Trial Evaluation - This evaluation consisted of question related to both the usability and acceptability of the software and the hardware.

- An Issues Register - This was designed to capture any specific issues that the users had with either the hardware or the software.

In addition to the user evaluation checklists, the researchers planned to use the following objective performance measures:

- Staff time required to complete tagout processes

- Staff time required to complete ACPS logs

- Data entry errors

- Errors tagging incorrect equipment

- Time required to update task status

- Overall equipment restoration time

- Management time required to status and manage task implementation

- User experience with the software and handhelds

Researchers were also prepared to interview plant personnel about their experience using the technology. Researchers asked the following questions:

- Does the technology allow better anticipation of potential problems?

- Does the technology promote more or less efficient work processes and teamwork?

- Does the technology and process increase trust (between the management team and the field workers) that allows critical decisions to be made with high reliability?

- Does the demonstration technology provide real-time monitoring of task progress?

- Does the technology support involvement of operations personnel at the right time to make the right decisions?

- Does the proposed approach provide the best information system possible with an emphasis on the importance of plant status in real-time? 


\section{RESULTS}

\subsection{Conditions Affecting the Research Outcomes}

As the research team prepared for the field demonstration of the technology at the Byron NPP, a serious operational condition emerged in a plant system (steam leak). Plant personnel who were dedicated to the research demonstration were required to assist in solving the plant issues and were not able to fully participate in the field demonstration. Other workers were requested to participate in the demonstration, received training, and a limited number of field demonstrations were able to be performed. As new participants were recruited to demonstrate the technology, represented employees were asked to complete the human subject research consent forms. Union representatives requested a copy of the form for evaluation. A form was provided and members of the represented workers (union) declined to participate further in the testing and evaluation of the technology.

The conditions mentioned above limited the data that could be collected by the team in two areas. 1) Completion of the Pre-trial, Post-trial and Issues Register data collection that was uploaded on the handhelds, and 2) performance data that was designed to measure the actual effect the new technology had on process efficiency (i.e. time to complete the tagging and logging process, data entry errors, and overall equipment restoration time).

Although data capture opportunities were limited by unforeseen plant events, a number of field tests were able to be conducted and feedback was obtained from interviews with Byron plant personnel. The following interview responses provided the team with helpful insight on how the technology would be important to future outage efficiency efforts.

\subsection{Results From the Interview Questions}

\section{Does the technology allow better anticipation of potential problems?}

There was a general agreement that the more lead time an outage team has to anticipate problems, the better decisions that will be made. By receiving real-time task information, outage managers felt they would be capable of anticipating resource and timing needs with greater accuracy. Participants felt that the technology as applied to the test procedure provided the best solution they had seen to solving the "Real-time Truth" dilemma and could easily be adapted for other tasks that required feedback on task progress. Team participants recommended that the technology be applied to more complex situations and tasks to further identify technology needs and opportunities. There was a specific recommendation to apply this type of process/technology to the problems surrounding emerging issues in outage and emergency response.

\section{Does the technology promote more or less efficient work processes and teamwork?}

Some team members responded that the more outage managers know about activities in the field, the more "comfortable" the outage management task becomes, which again, results in better decision-making. The process of figuring out the status of field work and field progress would become less arduous as the technology was fully leveraged against multiple field tasks. Outage team members reported that they always worry about activities or issues that can impinge on the critical path. By using the capabilities of the technology, outage managers reported that they "can become part of the solution rather than spending a majority of time attempting to update the status of their tasks".

The capability of seeing the progress on multiple tasks would promote teamwork where multiple activities needed to occur in tandem or in a linear fashion. Managers in the OCC and the WEC reported that the connectivity achieved by use of the SMART boards increased teamwork and reduced travel time between the two functions. They also reported that the part that was missing was the information from the field and that this demonstration is a good start at addressing that shortcoming. 


\section{Does the technology and process increase trust (between the management team and the field workers) that allows critical decisions to be made with high reliability?}

Participants responded that this question has not been fully resolved. A number of employees felt that the new technologies could be used either way by outage managers, and that the positive effects of the technology upgrades could be affected by cultural issues present in the outage environment. One respondent indicated that if the technology was used appropriately, the accountability between outage managers/supervisors and field workers would become a shared responsibility. This would be especially relevant when high-hazard tasks are authorized by managers and carried out by field personnel. The responsibility for error would become a shared accountability the way the technology is currently configured. This was seen as a positive attribute of the technology.

\section{Does the demonstration technology provides real-time monitoring of task progress?}

Respondents overwhelmingly agreed that the demonstration technology has the potential to provide real-time monitoring, provided that some technological issues can be resolved. These include areas that are not currently covered by $\mathrm{WiFi}$, not prohibited by security issues, and that the physical work environment does not prohibit the use of hand-held technologies (i.e., working at heights, high radiation areas due to PPE concerns, etc.). Bluetooth and other hands-free devices were recommended for further study.

\section{Does the proposed technology involve Operations personnel at the right time to make the right decisions?}

Respondents commented that as the capabilities evolve, the technology could be used by key decision makers using the net-meeting approach. There is a desire to expand the use of the technology (see emerging issues above) to create an environment where the capabilities of the technology can display video, still pictures, schematics, maintenance history and other features to allow informed decision making by selected outage team members. This may include vendors, suppliers, task schedulers, and other experts.

\section{Does the proposed approach provide the best information system possible with an emphasis on the importance of plant status in real-time?}

Team members and participants agreed that the technology, as proposed, provided the best solution to date but further refinement of the technology and a better understanding of the uses is required before this could be accomplished. Linking with the plant control room should be considered. One respondent commented that the real value of this demonstration was not the new technology per se, but the way it is applied to solving some of their most pressing outage problems.

\subsection{General Comments}

The participants felt that the demonstrated process would substantially reduce human error. The teaming approach to "work" provided workers and management with an increased sense of communication and accountability (identified by participants as a key success attribute) when using the technology.

- The Samsung 5" Tablet was preferred by users (relatively inexpensive and capable of being held in one hand),

- Automated form creation was seen as a benefit to reduce field error and save time,

- The software produced an auditable record without additional paperwork, 
- Streaming video (although somewhat restricted due to a throttled-down guest WiFi network used in the demonstration) allowed real-time information sharing that could be used in dynamic conditions such as the rate/extent of leaks and the assessment of rapidly changing conditions,

- Modification / adaptability of the software is quick and inexpensive. The social network platform that the software is built on enables plants to adapt the technology to other uses that support outage efficiency (i.e. plant rounds, and quality assurance functions).

During the demonstration the research team also collected information about challenges and opportunities related to using the proposed technology. The identified challenges are listed below.

- In WiFi mode, plants may have some coverage issues (Offline mode is usable and data is recorded until user reaches Wi-Fi enabled area)

- Some bar codes may not be readable (damaged or other non-standard formats)

- Apple "Touch" not fully functional and was least desirable hand-held

- Use of hand-helds in hazardous or radiation areas not tested (gloves may hinder data entry)

- Plants may experience some resistance and/or learning difficulties by older workers or workers not familiar with new technologies,

- Represented employees may question use of new equipment,

- GPS locator may meet some resistance by personnel when enabled,

- Limited wireless capabilities in some plants may limit use in real-time.

The identified opportunities related to using technology to improve the availability and usage of real-time truth are listed below.

- Applicable for broad use in plant systems and support functions

- Plant rounds, rad-con mapping, emerging issues management, remote conferencing and multi-media decision making is possible

- Blending with other technologies will be possible (i.e., heads-up micro-displays, radiation visualization, etc.)

- The Ovalpath software can be rapidly adapted to changing user needs, as demonstrated by the quick reconfiguration of software and features by Ovalpath in response to user feedback and radiation control needs.

\subsection{Important Lessons Learned}

The research team gained many important lessons learned that can be applied directly to efficiency upgrades during continued research efforts. One of the most important insights is that change management is perhaps harder than technology deployment. As conditions change in operating nuclear plants, researchers and technology deployment personnel must realize that plant safety and on-line production may usurp the opportunity to deploy new technologies. It is also vital that new initiatives address cultural issues, such as acceptance of technology, tolerance for problems, reluctance for video records of the work (employee trust issues) etc., as well as addressing plant environmental issues, e.g., stress of plant problems and union concerns. 


\section{CONCLUSIONS}

This ongoing LWRS pilot research project demonstrated that existing technologies can be configured to solve many of the complex problems associated with outage management. All of the concepts and technologies worked as expected to the extent that they could be tested. While some barriers were present in the deployment of the technologies, the research established the foundation for continuing efficiency and safety initiatives which can be demonstrated and applied in a cost competitive method as applied to outage management. These technological capabilities were found to be important to the Exelon commercial nuclear plant that participated in the research. Exelon has made a decision to move forward with these capabilities (Ovalpath and handhelds) to enhance their competitive posture and to assist in sustaining the efficient life of the Byron facility.

The results from the data collection conducted during the demonstration are consistent with the hypothesis. Even though the data collection activities were curtailed due to unforeseen circumstances (i.e., an unforeseen plant event that diverted personnel from participating and represented employees declining to participate), the research team was able to demonstrate that the technology can be successfully deployed to address many of the challenges in outage management. The research team was able to successfully demonstrate the salient features of the scenarios they developed and how the technology can mitigate some of the challenges in those scenarios. Additionally, the results from the interviews indicate that by creating a system where real-time outage information is available, potential issues can be anticipated before they escalate to major issues. By using technology, a shared problem solving environment can be created, which may facilitate high quality decision-making during outages and efficient and safer outage task execution.

During the course of the research effort the research team gained important insights that will be utilized when planning for future activities. The insights will help mitigate less desirable situations that could potentially have a negative impact on the progression and outcome of the research effort. Examples of insights are:

- Great care should be taken prior to introducing new technology into a scheduled outage scenario,

- When installing new technology, allow enough lead time for plant personnel to install and test the equipment,

- Assure that all technical constraints and requirements are sufficiently addressed to allow for the installation of new technology,

- Assure that all the potential participants are aware of the requirements associated with the research (e.g., informed consent) before the scheduled research activities and that any potential concerns are mitigated before the research is scheduled to start,

- Assure that there is a back-up plan for conducting the research in the event that the data collection does not go as planned.

In relation to the demonstration study, the research team learned that the utility might have different priorities than the research team, which could affect the scheduling and resources available to support the research effort. The team also learned the importance of involving the right groups at the utility needed to install the technology. It is important to identify the possibility that the utility has other commitments or priorities. It is also important to identify what resources are needed to complete the installation in a timely manner as well as identify what technical constraints or requirements (such as sufficient electrical power) must be addressed before proceeding with the installation. The research team found that technical issues could easily be addressed and resolved by actively involving vendors and plant personnel such as the IT department and the Operations department in the deployment process.

The research team also worked in collaboration with the vendors and the plant IT department to develop and present the training needed for the demonstration and data collection. This approach resulted in a high level of engagement with the outage team members. 
Results of the research have been shared with the LWRS Advanced II\&C members and at various professional conferences and workshops over the past months. Feedback from these presentations indicates a great deal of interest by several utilities and international organizations. Collaboration opportunities are available for demonstration and testing at US utilities, and with EDF/Paris and the IFE Halden Reactor Project in Halden, Norway. Members of the LWRS Working Group and others strongly encouraged further testing and demonstration of the technology upgrades and process improvements developed in this study.

The next phase of the research effort will leverage the insights from the conducted research activities. The insights will be applied to addressing outage emerging issues at a major US nuclear utility as well as establishing the core capabilities for the efficient redesign of the next generation of outage control centers. It is hoped that the data collection activities can be completed through this opportunity. Continuing research and commercial teaming efforts are scheduled through FY 2017. 


\section{REFERENCES}

Gertman, D., Blackman, H., Marble, J. Byers, J., Smith, C. (2005). The SPAR-H human reliability analysis method, NUREG/CR-6883, US Nuclear Regulatory Commission.

Gomes, C. P. (1996). Automatic scheduling of outages in nuclear power plants with time windows. Rome Lab Tech Report. RL-TR-96-157.

Hildebrandt, M., Koskinen, H. (2011). Success Factors for Organizing Outage Control Centers Preliminary Results. Halden Reactor Project. HWR-972.

International Atomic Energy Agency. (2006). Indicators for managements of planned outages in nuclear power plants. IAEA-TECDOC-1490.

Mora, M., Guisseppi A. Forgionne, Jatinder N.D. Gupta. (2003). Decision Making Support Systems: Achievements, Trends, and Challenges for the New Decade. Idea Group Publishing.

Oxstrand, J., Boring, R., Farris, R. (2011). Advanced instrumentation, information and control (II\&C) research and development facility buildout and project execution of LWRS II\&C pilot projects $1,2 \&$ 3. INL/LTD-11-21620. 


\section{Appendix A}

\section{LWRS Pilot Project Technology Demonstration: Increasing Efficiency of Operations and Maintenance Related Tasks at Nuclear Plants January 2012}

Objective: To provide technology that improves the efficiency of performing equipment manipulations or task specific maintenance and outage activity at nuclear plants.

Description of Capabilities: The INL, working closely with Exelon Nuclear and Ovalpath, Inc. has developed a prototype efficiency improvement methodology based on Ovalpaths "Wizzpers" software and commercially available smartphone and smartpad technology. For the demonstration, the Wizzpers software will run on a web-based server outside of Exelon's secure internal servers/databases. INL will use projectdedicated funds to secure a short-term purchase of Ovalpath licenses for the purpose of technology demonstration. Various handheld devices, purchased by INL and Exelon will be loaded with the Wizzpers software and plant personnel will have access to each of the devices for the purpose of testing usability of both the Wizzpers application and the devices themselves. INL researchers will monitor the demonstration and receive feedback on the technology applications.

Motivation: Although advances in communication and efficiency technologies have made major steps forward over the past several years, many maintenance and operational functions are not effectively managed even in the most efficient nuclear plants. Plant and task status updates are delayed, personnel are difficult to locate, errors are made in equipment identification, paper-based recordkeeping is not accurate or immediately retrievable, and plant clearances are not well coordinated...delaying work crews and losing critical work time. The purpose of this applied research is to demonstrate how technology can improve the efficiency of work tasks at nuclear facilities and to evaluate the technology for outage and emerging issues management applications.

Extended Outlook: Upon completion of a successful demonstration project, the technologies and lessons learned may be expanded for use in plant outage activities and as a mobile platform that manages emerging issues at nuclear and industrial sites.

\section{Technology Demonstration Breakdown}

The technology demonstration will consist of:

Stage 1: Control of Equipment and System Status

Stage 1 of the demonstration will use hand-held technologies to track and status work activities associated with Exelon's procedure: OP-AA-108-101, Control of Equipment and System Status. The hand-held devices will be supported by Ovalpath web-based software that enables personnel performing activities involving equipment manipulations to maintain proper operational configuration of plant systems.

The purpose of the demonstration is to determine if the technology results in an increase in efficiency while performing the procedure and to increase management's situational 
awareness of the current status of field activities and crews. Specifically, the demonstration will measure:

- Staff time required to complete tagout process

- Staff time required to complete ACPS logs

- Data entry errors

- Errors tagging incorrect equipment

- Time required to update task status

- Overall equipment restoration time

- Management time required to status and manage task implementation

- User experience with the software and handhelds

The demonstration is scheduled to begin February 22, 2012 with final arrangements and training to be completed on February 20 and 21. This includes loading the software, configuring the Smartboard to monitor activities in a location compatible with management oversight, employee training, and arrangements for all team training and security clearances.

The Exelon employees involved in the equipment demonstration will be asked to fill out a survey (residing on the various handheld devices) that describes their interaction with the Ovalpath software, the handheld devices themselves, and the efficacy of the process or task that they are involved in. The data collected from the surveys, as well as the data collected from the process itself will be stored on the ovalpath software and be available for evaluation during and after the demonstration period. The data will be analyzed and made available to nuclear utilities as part of the LWRS outage improvement initiative. The demonstration will be conducted on actual plant equipment, not in the Byron training facility. The Exelon Operations Manager will select the tasks that will be used in the demonstration. The demonstration will be conducted between February 23 and March 7 , 2012. Exelon work crews and supervisory personnel will record their work experiences with a pre-loaded survey that resides on each handheld (or is accessible from the handhelds). During the 15 day demonstration period, Exelon should perform a minimum of 45 work tasks where the handhelds are used to assure an adequate number of worker experiences are obtained for evaluation. The greater the number of uses, the more valid the demonstration becomes. Once a survey is completed the results will be automatically transmitted to the research team for evaluation. Management, work crews, and the research team will also be capable of transmitting information between handhelds and the smartboard.

Although the actual demonstration period ends on March 7, 2012, Exelon may continue to use the Ovalpath software and government-owned handhelds for up to 60 days.

Contractual arrangements with Ovalpath during the demonstration period end after 60 days unless modified.

The research team and Ovalpath personnel will be on-site during the week of demonstration start-up. Remote monitoring of demonstration activities will be conducted during the week of February 27 by both INL and Ovalpath personnel. The INL research team will return to the Byron facility during the week of March 8, 2012 where debriefs will be conducted with demonstration participants.

During the demonstration period, Ovalpath technical personnel will be available (remotely) to assure that the software is operating properly and as intended to support the demonstration goals. 


\begin{tabular}{|c|c|c|c|c|}
\hline Task & Description & Responsibility & $\begin{array}{l}\text { Timeframe } \\
\text { or Due Date }\end{array}$ & Notes \\
\hline \multicolumn{5}{|c|}{ 1.0 Demonstration Planning } \\
\hline 1.1 & $\begin{array}{l}\text { Finalize Demo scope with } \\
\text { team }\end{array}$ & INL & $1 / 6 / 12$ & \\
\hline 1.2 & $\begin{array}{l}\text { Finalize funding/contract } \\
\text { for demo with Ovalpath }\end{array}$ & INL & $1 / 13 / 12$ & $\begin{array}{l}\text { INL to fund } \\
\text { demonstration } \\
\text { licenses. }\end{array}$ \\
\hline 1.3 & $\begin{array}{l}\text { Complete build-out of } \\
\text { demo software using } \\
\text { Ovalpath Wizzpers and } \\
\text { Exelon procedure OP-AA- } \\
108-101\end{array}$ & Ovalpath & $1 / 20 / 12$ & \\
\hline 1.4 & $\begin{array}{l}\text { Complete user survey to } \\
\text { be loaded on handhelds. }\end{array}$ & INL & $1 / 20 / 12$ & \\
\hline 1.5 & $\begin{array}{l}\text { Accept Demo software } \\
\text { package }\end{array}$ & INL/Exelon & $1 / 31 / 12$ & $\begin{array}{l}\text { Includes survey } \\
\text { upload. }\end{array}$ \\
\hline \multicolumn{5}{|c|}{2.0 Installation \& Preparation } \\
\hline 2.1 & $\begin{array}{l}\text { Coordinate installation of } \\
\text { Ovalpath software on } \\
\text { hand-helds. }\end{array}$ & Ovalpath & $2 / 10 / 12$ & $\begin{array}{l}\text { Can this be } \\
\text { loaded on } \\
\text { devices when } \\
\text { we arrive at } \\
\text { Byron? }\end{array}$ \\
\hline 2.2 & $\begin{array}{l}\text { Arrange for research team } \\
\text { training and security } \\
\text { clearances }\end{array}$ & Exelon & $2 / 10 / 12$ & $\begin{array}{l}\text { Is Training / } \\
\text { Security } \\
\text { available on } \\
\text { Monday the 20? }\end{array}$ \\
\hline 2.3 & $\begin{array}{l}\text { Arrange for central } \\
\text { location where handhelds } \\
\text { can be stored/recharged } \\
\text { and the Smartboard can } \\
\text { be hooked up. }\end{array}$ & Exelon & $2 / 10 / 12$ & $\begin{array}{l}\text { Demonstration } \\
\text { will be } \\
\text { conducted } \\
\text { during actual } \\
\text { work. }\end{array}$ \\
\hline 2.4 & $\begin{array}{l}\text { Demonstration kick-off } \\
\text { meeting. }\end{array}$ & $\begin{array}{c}\text { Exelon, INL and } \\
\text { Ovalpath } \\
\text { personnel. }\end{array}$ & $2 / 20 / 12$ & At Byron facility. \\
\hline 2.5 & $\begin{array}{l}\text { Complete installation of } \\
\text { demonstration hardware. }\end{array}$ & Exelon & $2 / 20 / 12$ & \\
\hline 2.6 & $\begin{array}{l}\text { Complete installation of } \\
\text { demonstration software. }\end{array}$ & Ovalpath & $2 / 20 / 12$ & \\
\hline 2.7 & Run test of system & $\begin{array}{l}\text { Exelon, INL, and } \\
\text { Ovalpath }\end{array}$ & $2 / 21 / 12$ & \\
\hline 2.8 & $\begin{array}{l}\text { Train Exelon personnel on } \\
\text { use of system. }\end{array}$ & $\begin{array}{l}\text { Exelon, INL and } \\
\text { Ovalpath }\end{array}$ & $2 / 21 / 12$ & $\begin{array}{l}\text { Exelon to } \\
\text { arrange room } \\
\text { and attendance. }\end{array}$ \\
\hline \multicolumn{5}{|c|}{ 3.0 Demonstration \& Data Collection } \\
\hline 3.1 & Demonstration Period & $\begin{array}{l}\text { Exelon, INL and } \\
\text { Ovalpath }\end{array}$ & $\begin{array}{l}2 / 22 / 12 \\
\text { through } \\
3 / 7 / 12\end{array}$ & $\begin{array}{l}\text { See description } \\
\text { above. }\end{array}$ \\
\hline 3.2 & Debrief at Byron & $\begin{array}{l}\text { Exelon and INL } \\
\text { Research Team }\end{array}$ & $\begin{array}{l}\text { Week of } \\
\text { March 5, } \\
2012\end{array}$ & \\
\hline 3.3 & Analyze data and prepare & INL Research & $3 / 2012$ & To be presented \\
\hline
\end{tabular}




\begin{tabular}{|l|l|l|l|l|}
\hline & report. & team & & $\begin{array}{l}\text { at Working } \\
\text { group meeting } \\
\text { and } \\
\text { Conferences. }\end{array}$ \\
\hline
\end{tabular}

Stage 2 Application of Stage 1 Lessons Learned to Outage and Emerging Issues Processes

Once the technology demonstration results have been compiled, a decision will be made regarding use of the capabilities in the outage and emerging issues processes. Separate technology demonstration proposals will be created for those activities. 


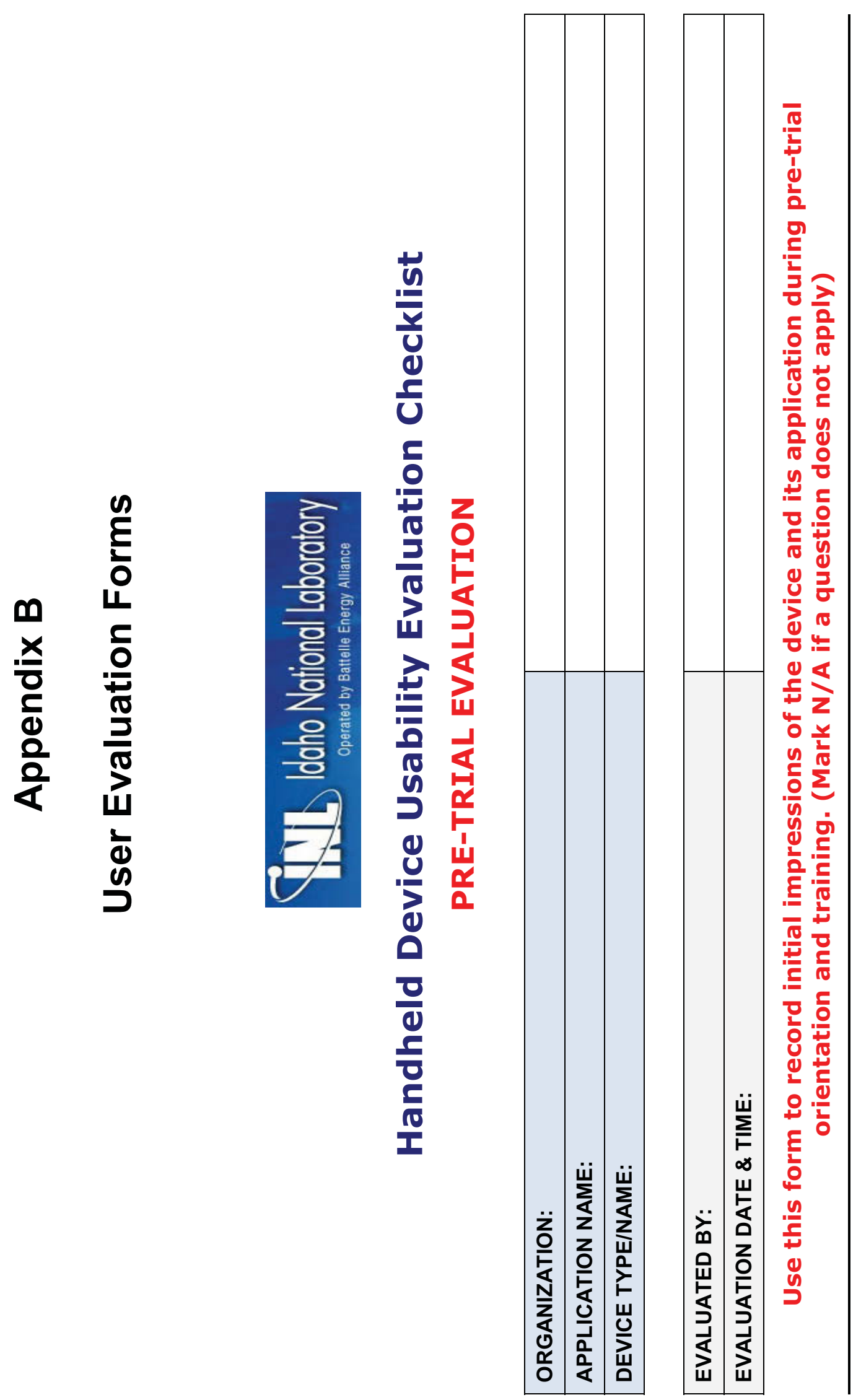




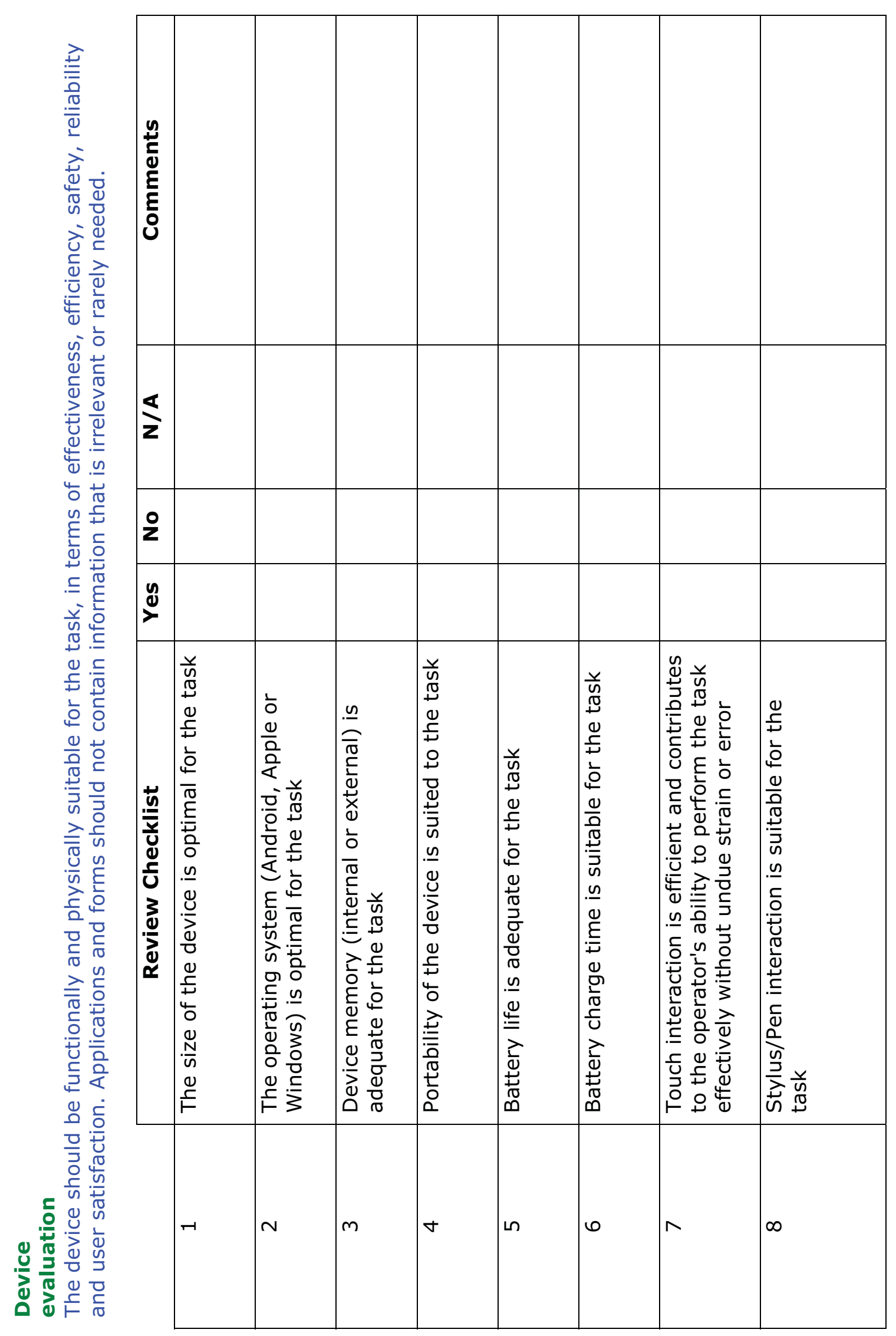




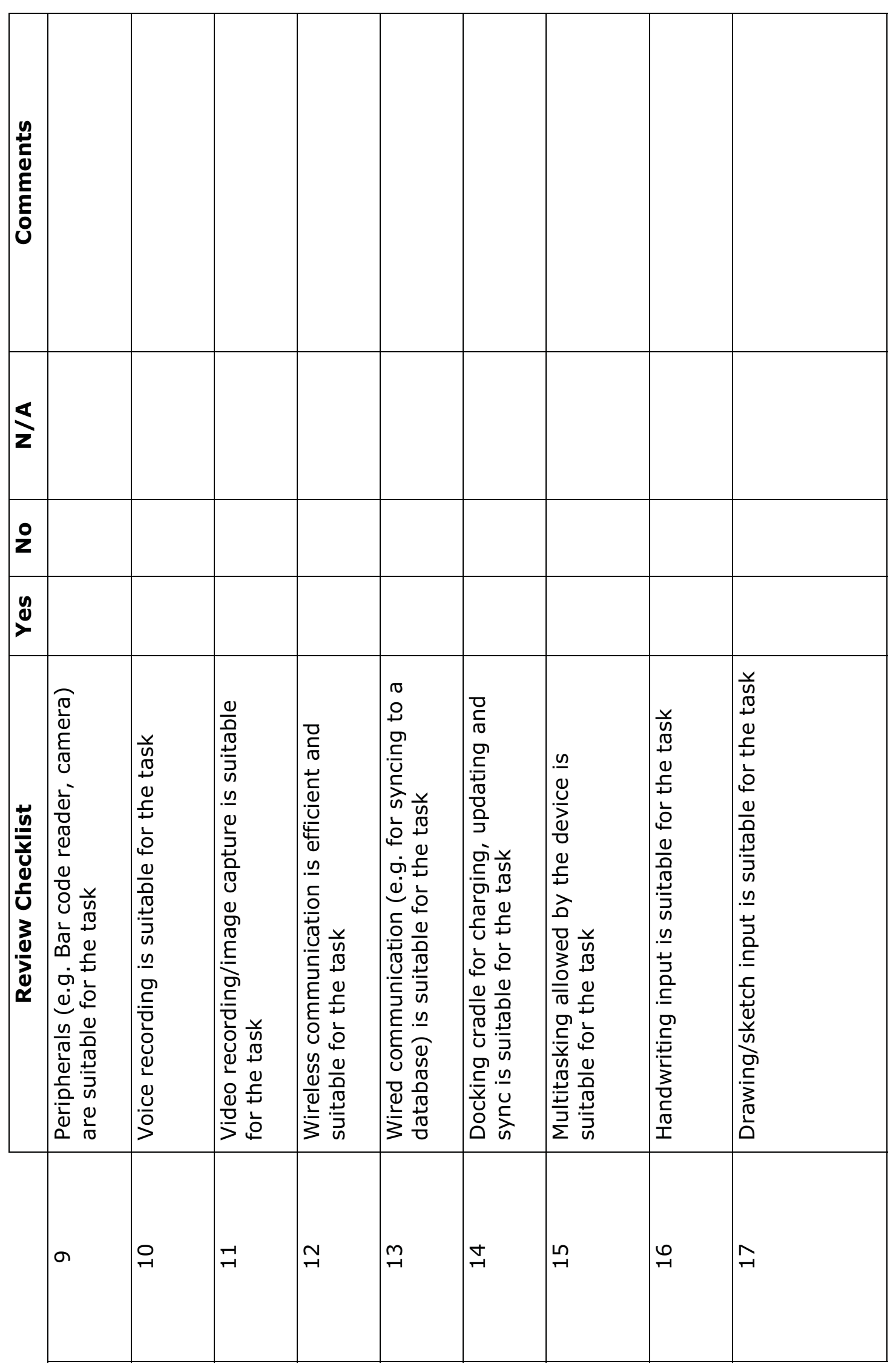




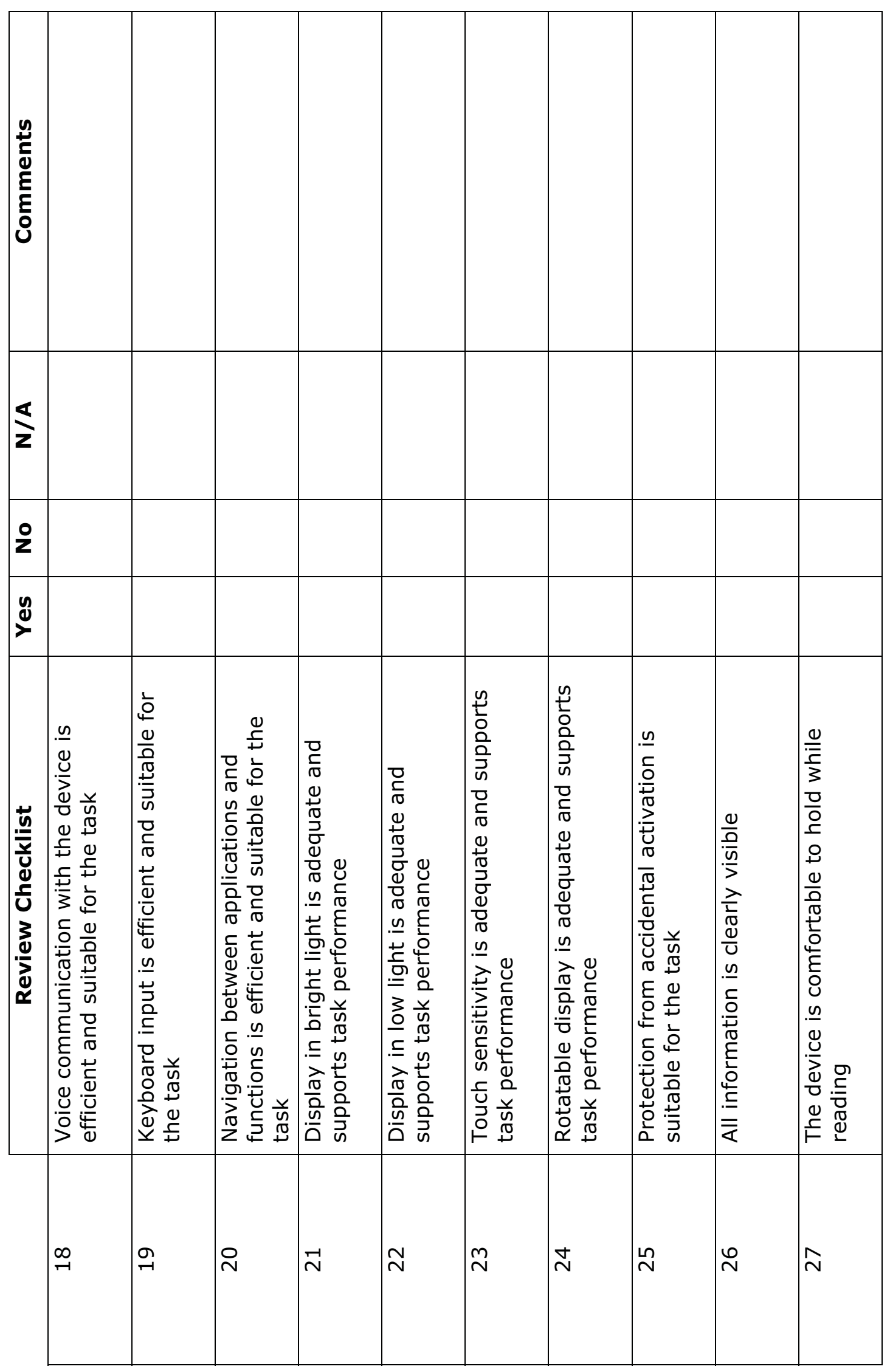




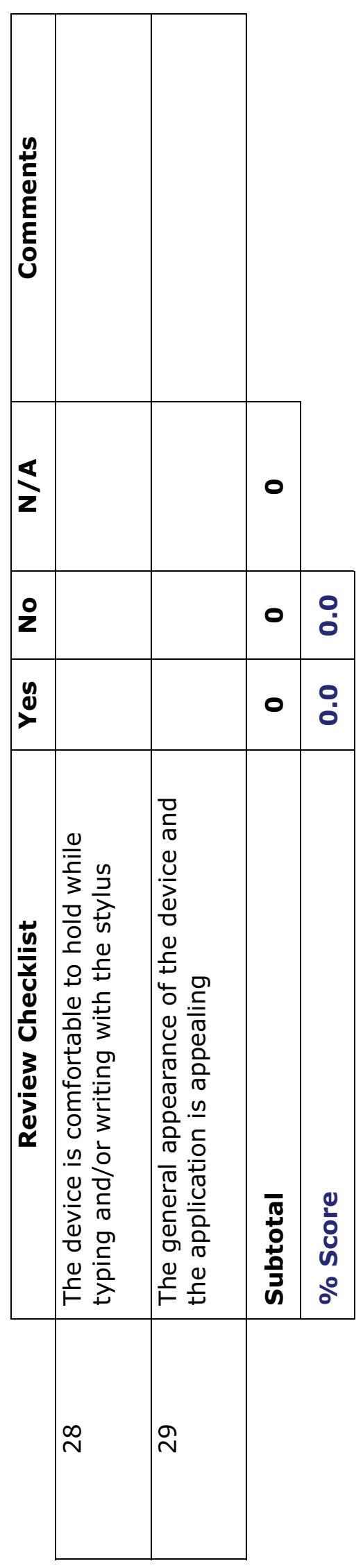




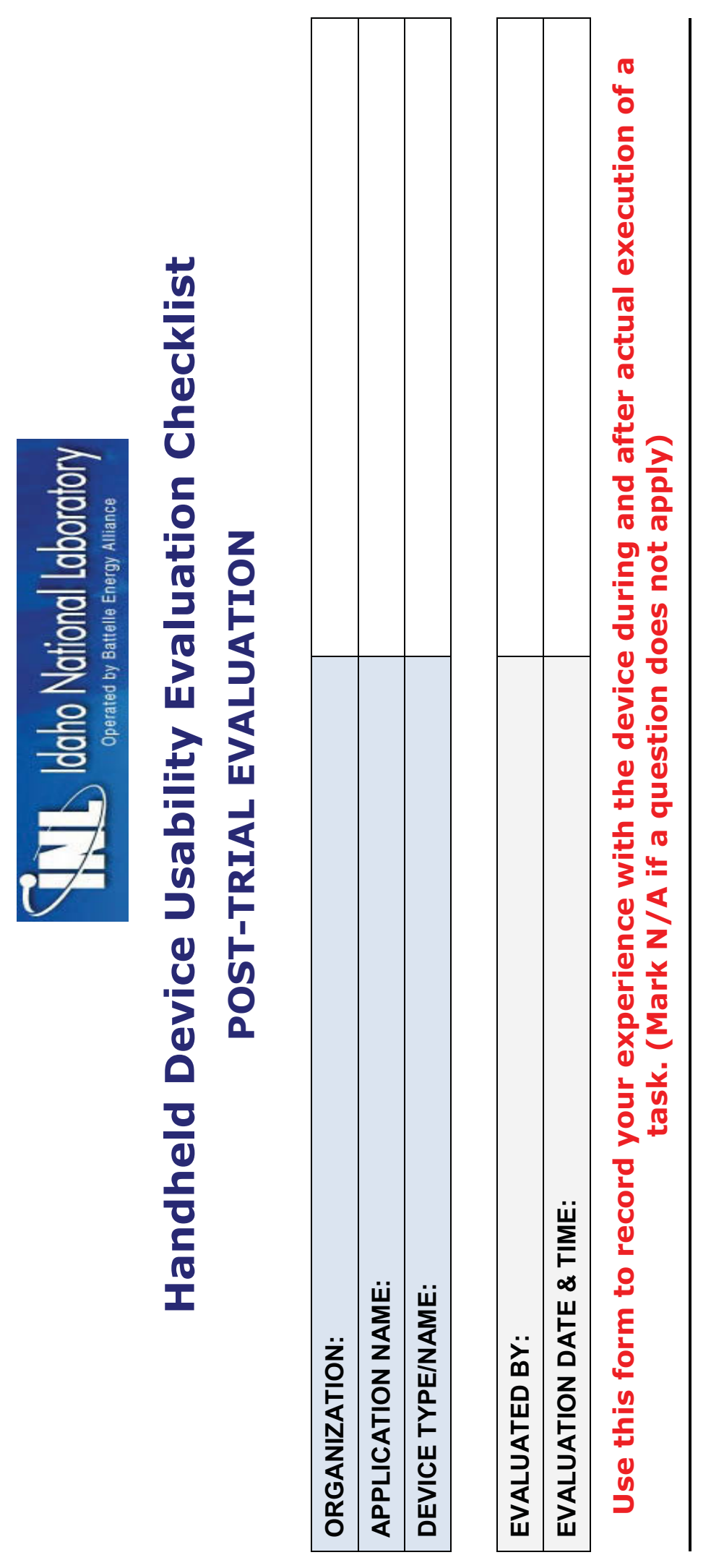




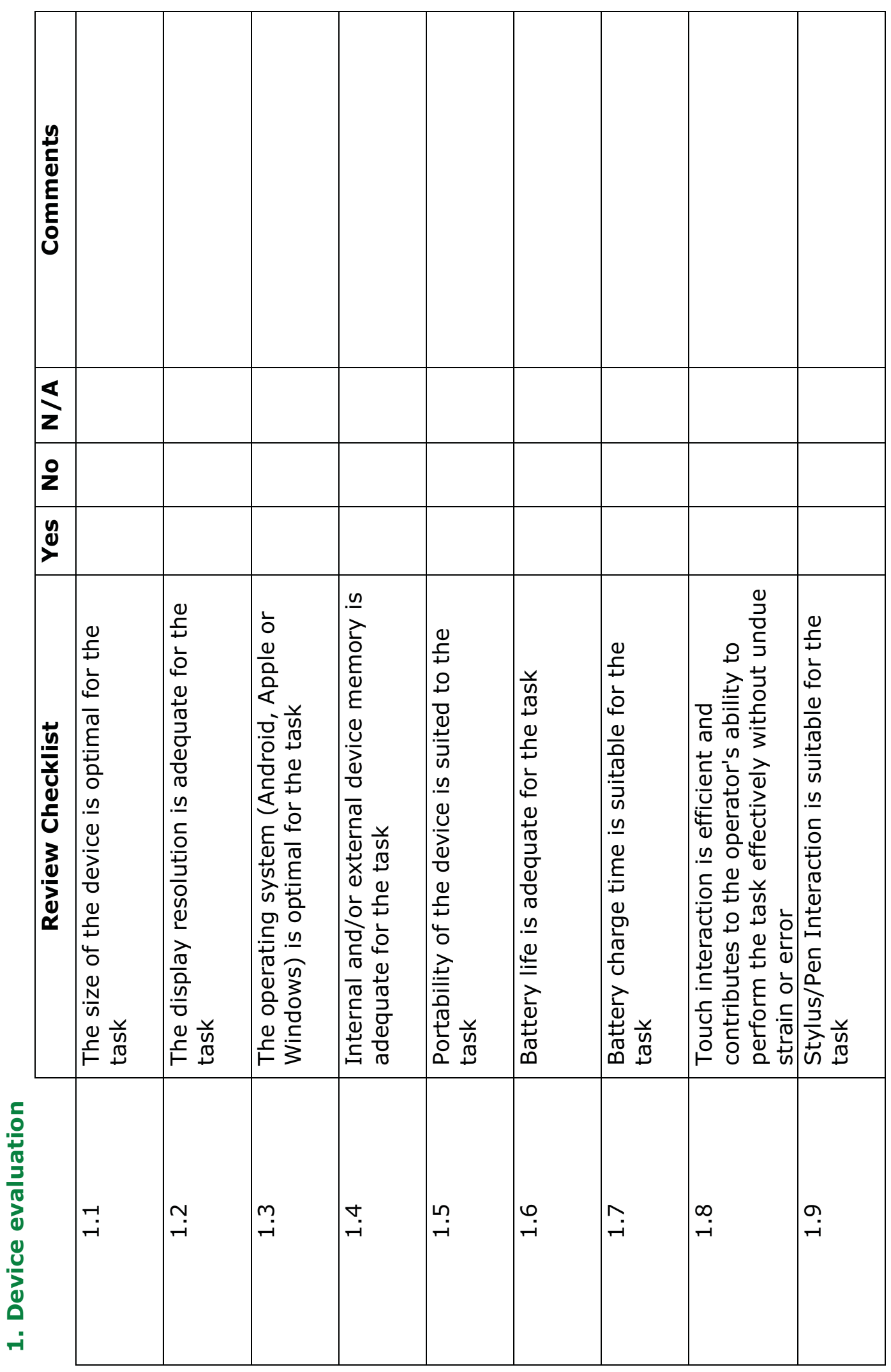




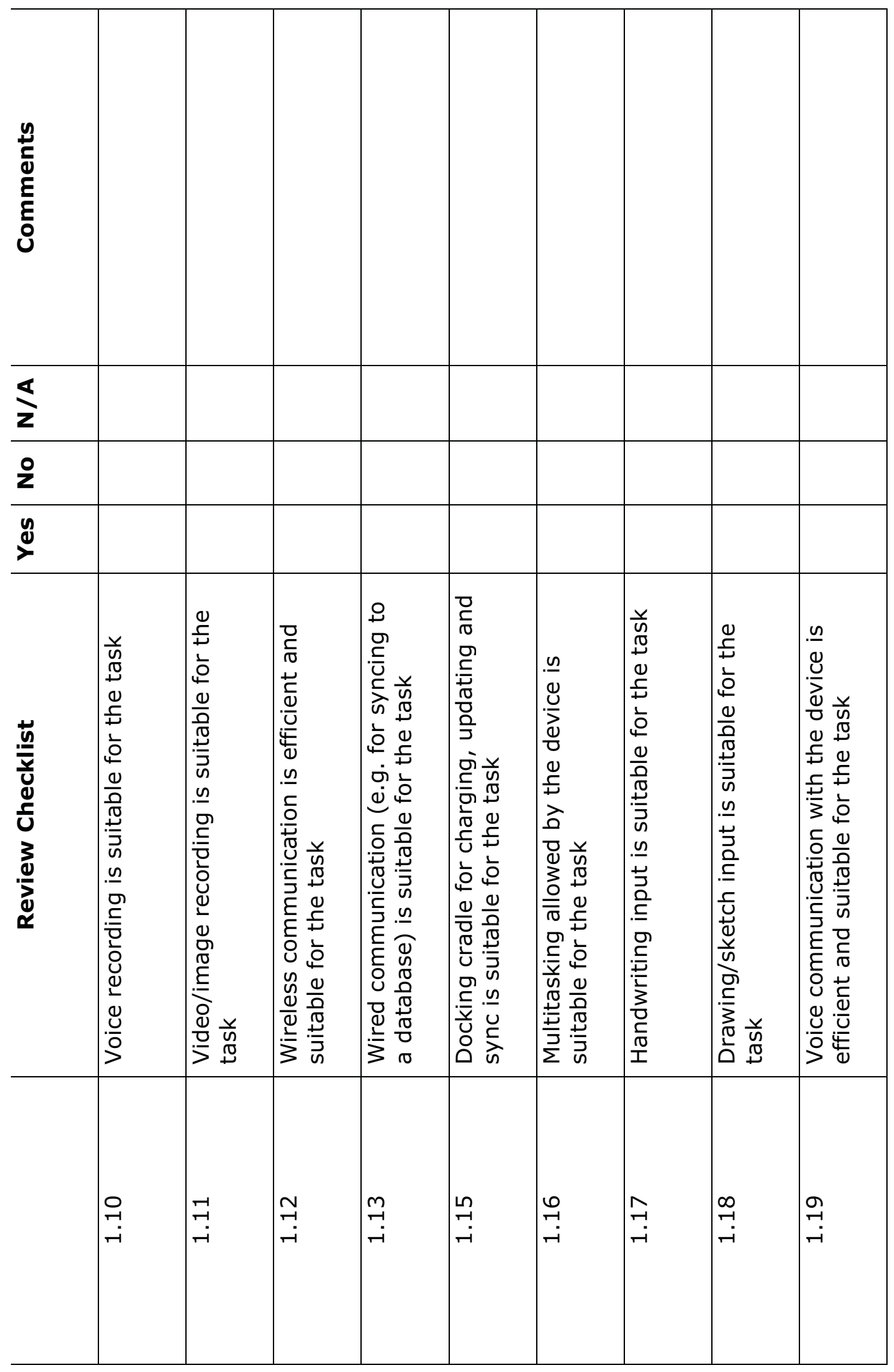




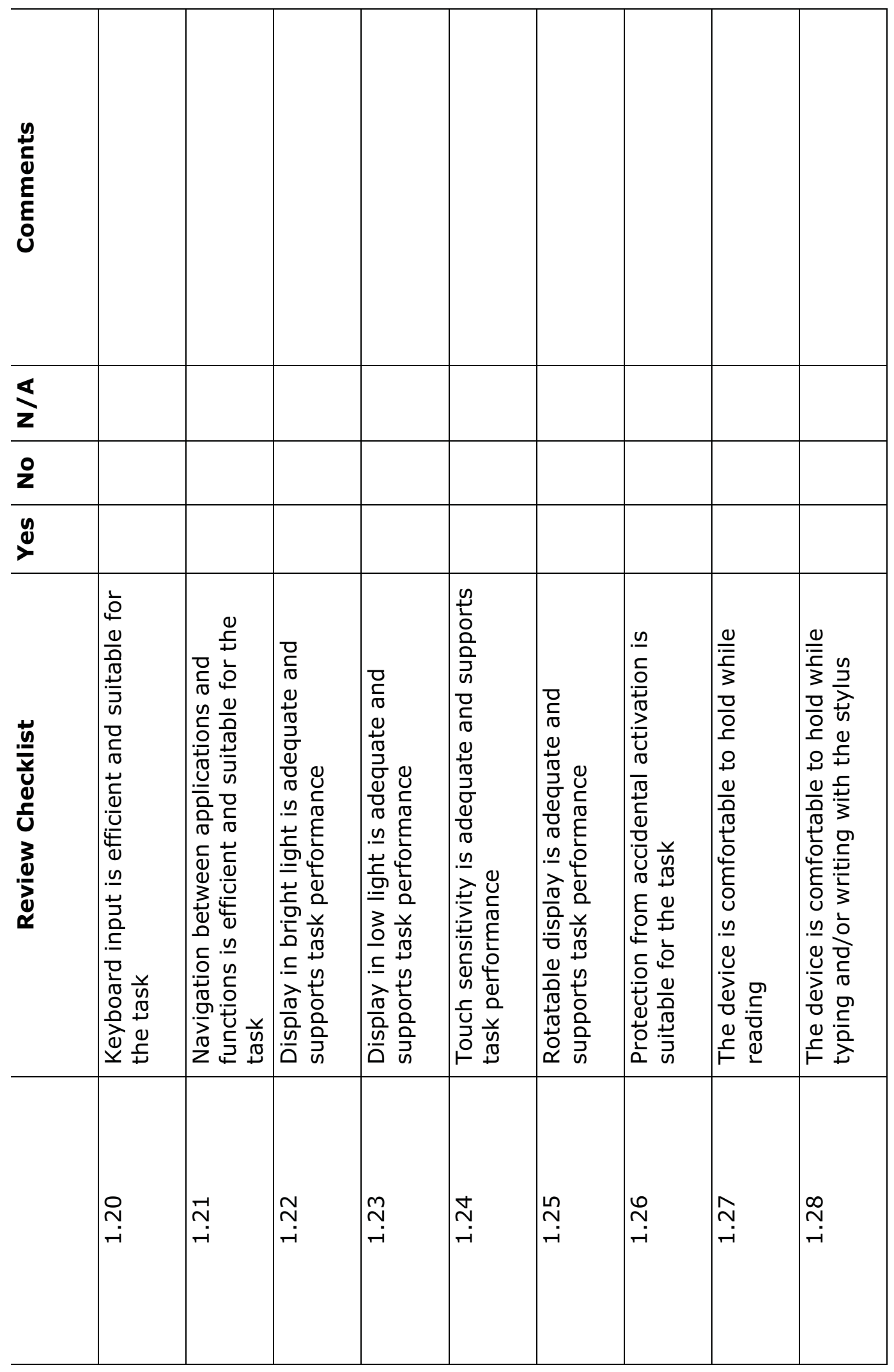



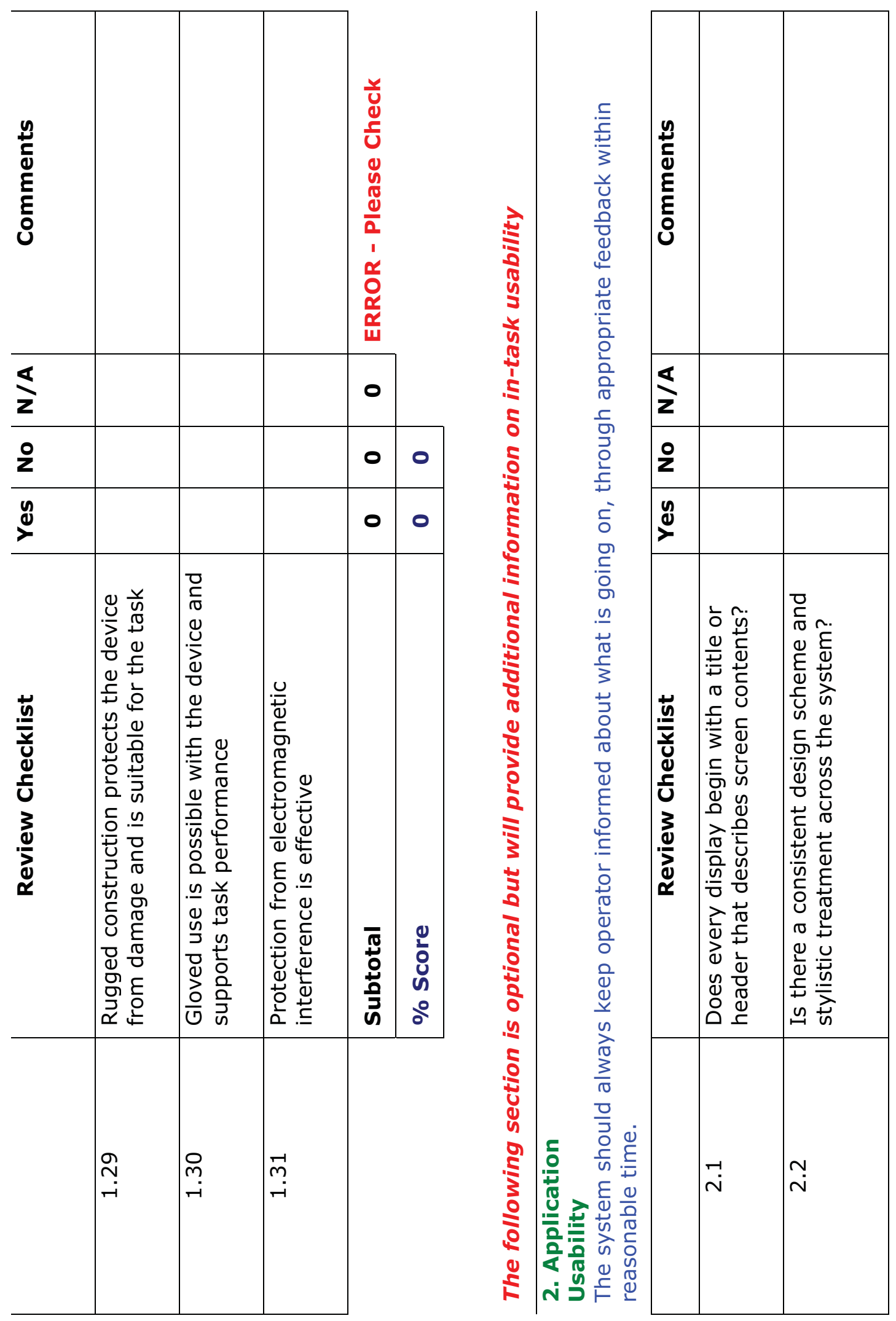


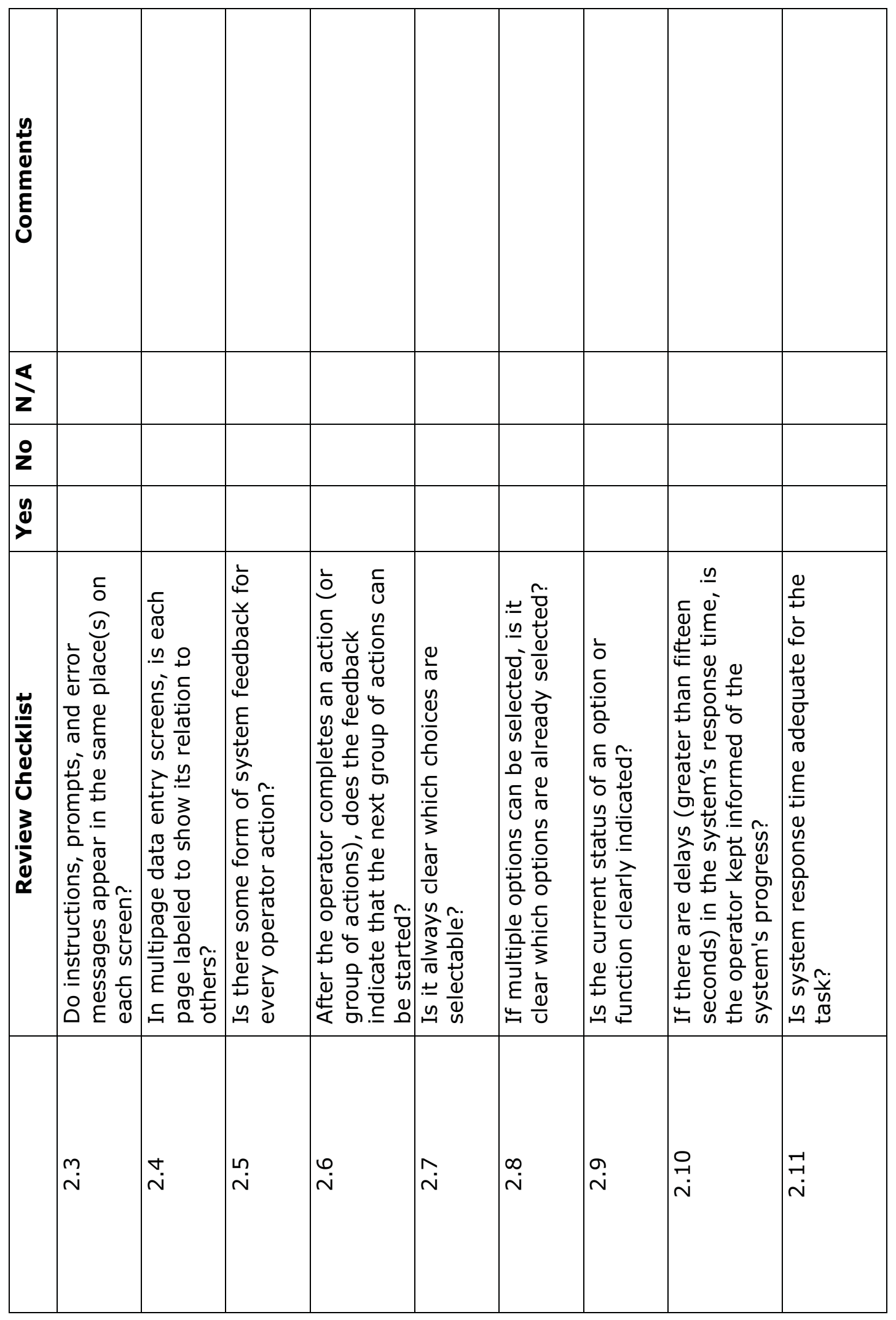




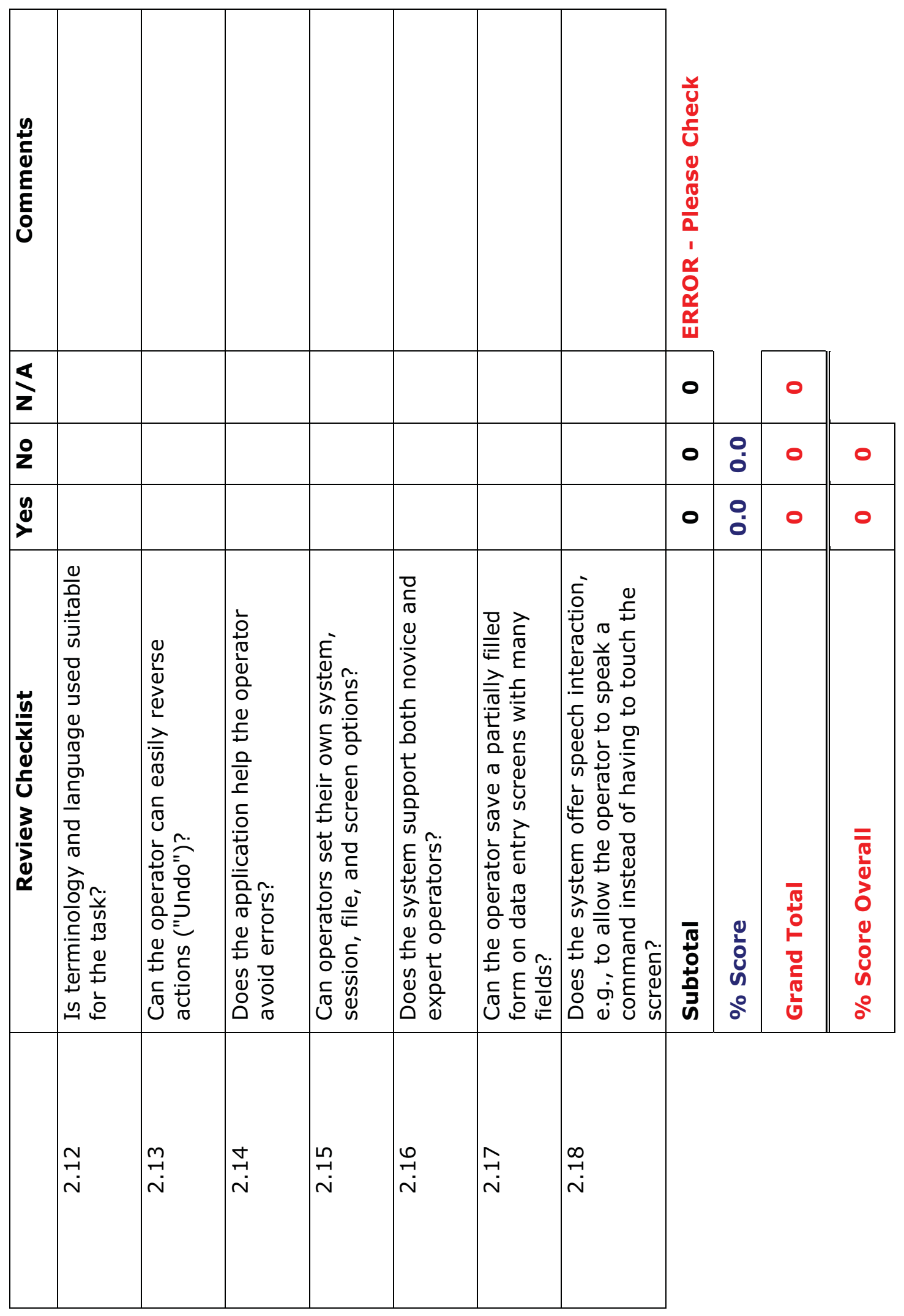

